Session 2592

\title{
The Effect of Stereotype Threat on Women's Performance on the Fundamentals of Engineering Exam
}

\author{
Amy E. Bell, Steven J. Spencer \\ Virginia Tech/University of Waterloo
}

\begin{abstract}
Recent research has demonstrated that stereotype threat- the concern that others will view one stereotypically_interferes with women's performance on standardized math exams. ${ }^{1}$ In the current study we examine whether stereotype threat interferes with women's performance on the Fundamentals of Engineering Exam (FEE). This exam is the first step in the process to become a licensed professional engineer. Sophomore and junior women and men engineering students completed one of two tests where the test questions were a subset of previous FEE questions. One test was comprised of primarily difficult questions while the other was made up of mostly easy questions. From a stereotype threat perspective, a student's concern about being stereotyped by others should be highest when two factors are at play: (i) the student is performing poorly (e.g. the questions are difficult); and, (ii) a stereotype might be applied to the student (e.g. the stereotype that women are not good at math). Based on previous research, it is in this situation that differences between men's and women's performance should emerge. The data in this study are consistent with this perspective: gender differences were evident only on difficult engineering questions after the engineering area expertise factor was controlled (i.e. normalized).
\end{abstract}

\section{Introduction}

Carl F. Gauss wrote the following in a letter to Sophie Germain: "A woman because of her sex and our prejudices encounters infinitely more obstacles than a man in familiarizing herself with complicated problems."2 Gauss's observation was true during the Napoleonic era and it remains accurate today_especially in some fields, like engineering.

The percentage of women earning bachelor's degrees in science and engineering in the U.S. reached 46\% in 1995 (up from 38\% in the mid-1980s). However, the percentages differ greatly by field. For instance, in 1995, women earned the following percentages of bachelor's degrees by field: $73 \%$ psychology; 50\% biological and agricultural sciences; 50\% social sciences; $33 \%$ physical sciences; 33\% earth, atmospheric, and ocean sciences; 33\% mathematics; 33\% computer science; and, $17 \%$ engineering ${ }^{3}$. The percentages of master's and doctorate engineering degrees awarded to women in 1995 were $16 \%$ and $12 \%$, respectively. ${ }^{3}$

The U.S. engineering bachelor's degree figures have steadily improved for women from $15.4 \%$ in 1990 to $18.6 \%$ in $1998 .{ }^{3,4}$ Unfortunately, this slow, steady increase is not necessarily 
evidenced at every institution. Indeed, the statistics for Virginia Tech (as depicted in Table 1) indicate a decline in the percentage of bachelor's degrees in engineering awarded to women over this time period.

\begin{tabular}{|l|r|r|r|r|r|r|r|c|}
\hline \multicolumn{1}{|c|}{ Degree } & 1990 & 1991 & 1992 & 1993 & 1994 & 1995 & 1996 & 1997 \\
\hline Bachelor & $18.5 \%$ & $18.3 \%$ & $16.2 \%$ & $13.9 \%$ & $18.3 \%$ & $17.6 \%$ & $15.8 \%$ & $16.2 \%$ \\
\hline Master & $15.3 \%$ & $20.3 \%$ & $16.4 \%$ & $16.7 \%$ & $15.0 \%$ & $17.8 \%$ & $17.8 \%$ & $18.2 \%$ \\
\hline Ph.D. & $1.0 \%$ & $12.4 \%$ & $10.1 \%$ & $9.5 \%$ & $7.6 \%$ & $13.5 \%$ & $8.0 \%$ & $12.1 \%$ \\
\hline
\end{tabular}

Table 1: Percentage of Virginia Tech bachelor's, master's and doctorate degrees in engineering awarded to women, 1990-1997..$^{5}$

On a positive note, the Virginia Tech figures for master's engineering degrees awarded to women increased over this time period and was higher than the national average in 1995 (also shown in Table 1).

Not only do women earn a disproportionately low share of the awarded engineering degrees, they also have lower retention rates than men. Table 2 shows the nationwide retention rates for women and men at three points in the undergraduate engineering pipeline for a 1982-1993 cohort. This data illustrates that the retention rates of women are lower at every point in the undergraduate engineering pipeline.

\begin{tabular}{|l|c|c|c|}
\hline Gender & $\begin{array}{c}\text { \% Retained after } \\
\text { threshold courses }\end{array}$ & $\begin{array}{c}\text { \% Retained beyond } \\
\text { threshold courses, } \\
\text { but before degree }\end{array}$ & $\begin{array}{c}\text { \% Completed } \\
\text { bachelor's degree }\end{array}$ \\
\hline Women & $77.3 \%$ & $64.6 \%$ & $41.9 \%$ \\
\hline Men & $81.7 \%$ & $80.0 \%$ & $61.6 \%$ \\
\hline
\end{tabular}

Table 2: Retention rates of women and men in undergraduate engineering at three points in the pipeline; $1982-1993$ cohort. $^{6}$

Paradoxically, although the degree completion rate for women is significantly lower than the rate for men, the grade point averages (GPAs) of women and men were nearly identical (GPA $=2.98$, standard deviation $=.437$ for women; $\mathrm{GPA}=2.88$, standard deviation $=.561$ for men $){ }^{6}$

Many studies have investigated the reasons why women remain persistently under-represented in science, mathematics, and engineering. Some of the primary reasons that are given to explain this phenomenon include: women's loss of confidence/lower self-confidence, ${ }^{7}$ a chilly classroom/learning environment for women, ${ }^{8}$ and women's innate inability with respect to science and mathematics. ${ }^{9,10}$

An innovative approach to understanding the lower performance of women on difficult math tests offers a new perspective on the performance and retention of women in fields that require a significant amount of mathematics, like engineering. This new approach suggests that -in addition to loss of self-confidence and chilly climate factors - the differences in women's 
performance and retention may be explained, at least in part, by the influence of stereotypes and prejudice on their performance. This influence has been characterized as stereotype threat.

Most of the research regarding prejudice and stereotyping has not addressed what it is like to be the target of the prejudice or stereotype. Research on stereotype threat, however, examines the experience of being in a situation where one risks being judged negatively due to a commonly held devaluing stereotype that exists about one's group. ${ }_{1,11,12,13,14,15}$ The primary hypothesis of stereotype threat research is that: when one is in a situation where a negative stereotype exists about one's group, then the additional fear of being judged or of self-fulfilling the stereotype, interferes with one's performance. For instance, women are generally considered to have lesser math abilities than men. So that when a woman finds herself in a situation where her math skills are being tested (e.g. a formal test or answering a question in class), she experiences a pressure that may degrade her performance.

An important difference between this explanation for women's under-performance on math tests and the explanation based on lower self-confidence is that stereotype threat only occurs in specific situations - situations in which the negative stereotype applies (i.e. when a woman is taking a difficult math test). In contrast, the self-confidence explanation is intrinsic to the person-it is felt in all situations.

Research on stereotype threat has demonstrated the dramatic impact of stereotype threat on women's performance on math tests. Women with strong math backgrounds perform worse than men with similar backgrounds on difficult tests-yet women perform equally well on easy tests. Moreover, when stereotype threat is increased right before the test is administered, women perform significantly worse than equally qualified men. Conversely, when stereotype threat is neutralized right before the test is administered, the difference in performance is eliminated. ${ }^{1,13}$

In addition to explaining differences in performance, stereotype threat may also illuminate the lower retention rates of women in math-related fields. Researchers have argued that the stereotype threat that women experience in math-related domains may cause them to "disidentify" with the domain. ${ }^{1,11}$ In other words, women may drop out of engineering in order to avoid the evaluative threat that they sometimes feel in this domain. Indeed, one study indicated that women expressed less interest in pursuing academic majors and careers involving high levels of mathematics after watching stereotypic TV commercials. ${ }^{13}$

In the present research we describe a preliminary experiment that indicates that stereotype threat may undermine women's performance on engineering exams. Specifically, we administered either an easy or a hard subset of questions from the general portion of the Fundamentals of Engineering Exam (FEE) to women and men engineering students. If stereotype threat undermines women's performance on the exam then we should see no difference between men's and women's performance on the easy exam-because any stereotype threat would presumably be eliminated by positive performance-but a gender difference should emerge on the difficult exam in which the stereotype about women's inability in engineering could serve as a threatening interpretation of the women's performance. 


\section{Method}

Thirty men and 18 women engineering sophomores and juniors at Virginia Tech participated in the experiment. Half of the women and half of the men were randomly assigned to take an easy version of the FEE and the other half of each gender were randomly assigned to take a difficult version of the FEE.

We developed the tests from questions available as practice tests for the general portion of the FEE. We reduced the number of questions and shortened the duration, but maintained the proportions of questions for each of the various engineering areas. The composition of the 18 questions were as follows: 6 math, 2 electric circuits, 2 statics, 2 chemistry, 1 thermodynamics, 1 dynamics, 1 material science, 1 computers, 1 ethics and 1 engineering economics.

The participants were recruited to participate in the study through email announcements. We only selected participants who indicated that they had a relatively high grade point average (GPA) in engineering, and who stated that they were good in engineering and that it was important for them to be good in engineering. We selected participants using these criteria because previous stereotype threat studies ${ }^{1,14}$ have indicated that stereotype threat effects are largest among the best students who are most identified with the subject matter.

Five to 10 participants reported to each testing session in mixed gender groups. They read the test instructions and were given 30 minutes to complete it. Upon completion the participants were thanked for their time, paid $\$ 10$, and the nature of the study was explained to them.

\section{Results}

Recall that our major prediction was that men and women would perform equally on the easier version of the FEE, but that women would under-perform in relation to men on the difficult version of the FEE. The results were mostly consistent with our predictions.

In analyzing the results we separated the math questions from the engineering questions. We did this for two reasons. First, a number of previous studies have demonstrated that stereotype threat can undermine women's performance in math [SPE99, STE02], and we wanted to test the impact of stereotype threat on engineering performance above and beyond its effects on math. Second, as it turned out the math questions that we selected from both the easy and the difficult test were relatively easy for our participants. Men and women performed quite well and equally so on both exams. Men got 78\% right and women got 79\% right on the easy exam, while men got $62 \%$ right and women got $61 \%$ right on the difficult exam.

The results for the engineering part of the exam were more interesting, however. In calculating a participant's score for this part of the exam we did not include questions that were directly related to the participant's major. The engineering major (i.e. expertise area) for each question is sometimes ambiguous. For instance, industrial and systems engineering (ISE) students take a materials science (MSE) course in their junior year; however, MSE is not an ISE expertise area. The final categorizations were determined by the required courses in the freshman and sophomore years only of each engineering department. For example, the 2 electric circuit 
questions were not included in the score calculation for electrical and computer engineering majors. However, the computers and ethics questions were included in the score calculation for all engineering majors. We did this because we reasoned that these questions would not be difficult for students majoring in these engineering disciplines. We refer to this as "controlling for area of expertise" or "controlling for engineering major". After controlling for area of expertise in this way we found that men and women performed equally on the easy engineering exam, whereas men performed better than women on the difficult engineering exam (as depicted in Figure 1). The difference between the two means was tested with a standard t-test with 22 degrees of freedom, and a value of 2.12 was obtained which is significant at the $95 \%$ level. This difference remained statistically significant even when controlling for GPA and self-reported competence and importance of engineering.

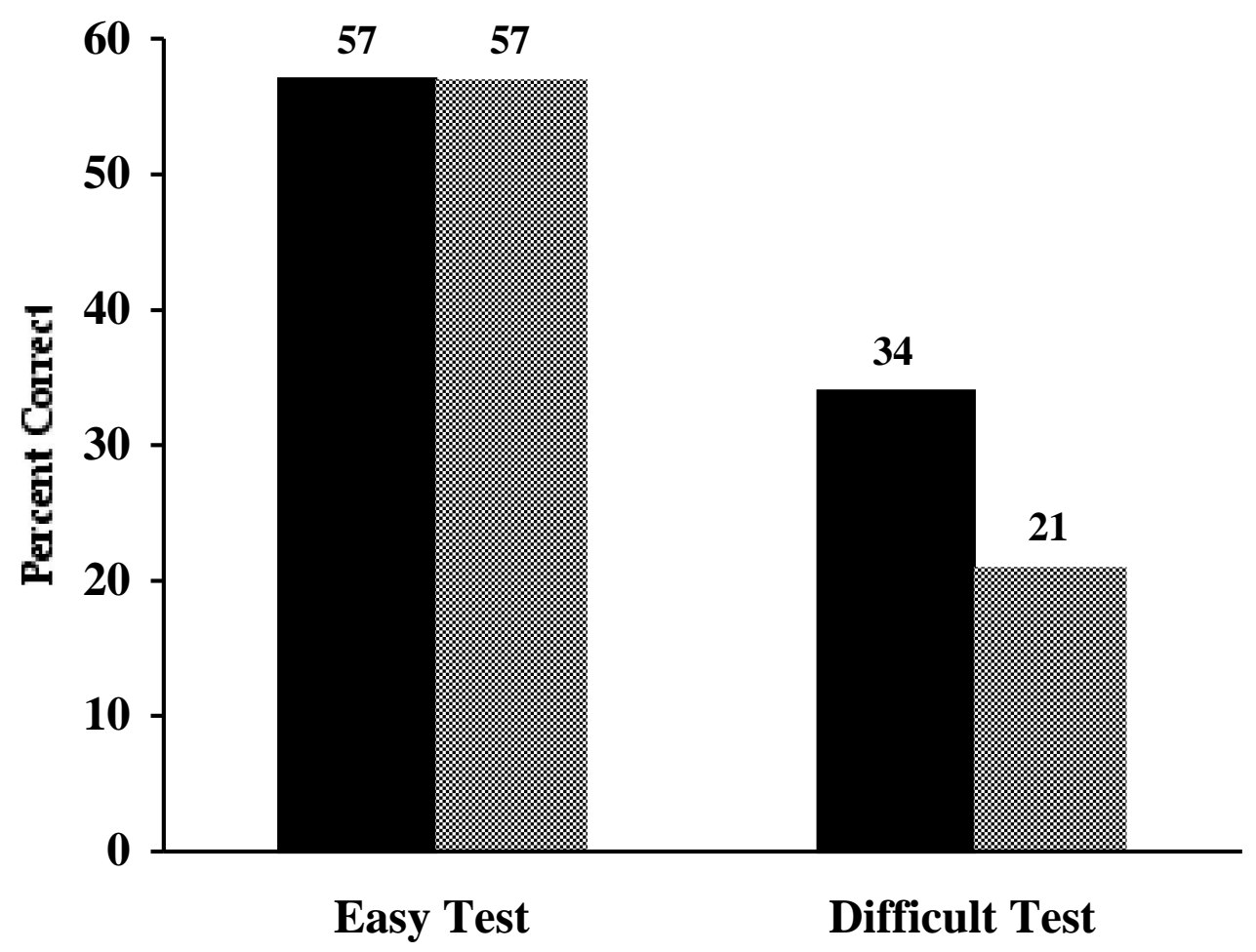

\section{-Men : Women}

Figure 1. Men's and women's performance on the engineering portion of the easy and difficult FEE tests after controlling for engineering major.

\section{Discussion}

The results of this study support the idea that stereotype threat can undermine women's performance on engineering exams, and thus extends previous research ${ }^{1}$ demonstrating that stereotype threat can undermine women's performance on math exams to engineering exams. Although the present study may not conclusively rule out the possibility that the hard engineering problems simply bring to light a gender difference that is not evident on the easy 
problems, such an interpretation seems unlikely for two reasons. First, it seems that such inherent differences in ability might well be reflected in math performance or in GPA as well as in performance on the easy engineering test-yet no such differences emerged. Second, the difficult items do not by and large test more complex engineering concepts, rather they test areas of engineering unfamiliar to the participants. It seems unlikely that only unfamiliar items would reveal true gender differences. However, stereotype threat should have its strongest effects on just such items. Even though the results of this study seem most consistent with a stereotype threat interpretation, it will require further research before we conclusively demonstrate that stereotype threat undermines women's performance on engineering exams.

Nevertheless, the current study does suggest that stereotype threat may be a more important impediment to women's success in engineering than has been realized. There might well be hope even given the rather depressing statistics reviewed earlier. If stereotype threat is undermining women's success in engineering then there are ways to reduce stereotype threat and increase women's success. If educators can create environments in which stereotype threat is low then more women should succeed. Perhaps in such an environment, in which many of the obstacles to women's success are removed, each woman will be able to familiarize "herself with complicated problems" of engineering and achieve the same level of success as her male colleagues.

\section{Acknowledgments}

The authors would like to thank Mr. Satyabrata Rout for his assistance in collecting the data in this experiment. This work was supported by a grant from the Alfred P. Sloan Foundation.

\section{References}

1. Spencer, S.J., Steele, C.M., and Quinn, D.M., "Stereotype Threat and Women's Math Performance," Journal of Experimental and Social Psychology, vol. 35, pp. 4-28, 1999.

2. $\quad$ Dalmedico, A.D., "Sophie Germain,” Scientific American, pp. 117-122, December 1991.

3. National Science Foundation (NSF), "Women, Minorities, and Persons with Disabilities in Science and Engineering: 1998,” NSF 99-87, Washington, D.C., 1999.

4. Engineering Workforce Commission of the AAES, "Engineering and Technology Enrollments," AAES, Washington, D.C., 1998 and 1999.

5. Virginia Tech Fact Book, Virginia Polytechnic Institute and State University, April 1999, http://fbox.vt.edu:10021/admin/ir/vtdata/fact99/.

6. Adelman, C., "Women and Men of the Engineering Path: A Model for Analyses of Undergraduate Careers," U.S. Department of Education and the National Institute for Science Education, Washington, D.C., 1998.

7. Seymour, E. and Hewitt, N.M., Talking About Leaving: Why Undergraduates Leave the Sciences, Westview Press, 1997.

8. Hall, R.M. and Sandler, B.R., "The Classroom Climate: A Chilly One for Women?," Project on the Status and Education of Women, Association of American Colleges, Washington, D.C., 1982.

Proceedings of the 2002 American Society for Engineering Education Annual Conference \& Exposition Copyright $($ ) 2002, American Society for Engineering Education 
9. Benbow, C.P. and Stanley, J.C., "Sex Differences in Mathematical Reasoning Ability: More Facts," Science, vol. 222, pp. 1029-1031, 1983.

10. Benbow, C.P. and Stanley, J.C., "Sex Differences in Mathematical Ability: Fact or Artifact?," Science, vol. 210, pp. 1262-1264, 1980.

11. Major, B., Spencer, S.J., Schmader, T., Wolfe, C.T., and Crocker, J., "Coping with Negative Stereotypes About Intellectual Performance: The Role of Psychological Disengagement," Personality and Social Psychology Bulletin, vol. 24, pp. 34-50, 1998.

12. Quinn, D.M., and Spencer, S.J., "How Stereotype Threat Interferes with Women's Math Performance," Journal of Social Issues, vol. 57, pp. 55-71, 2001.

13. Davies, P.G., Spencer, S.J., Quinn, D.M., and Gerhardstein, R., “All Consuming Images: How Demeaning Commercials that Elicit Stereotype Threat can Restrain Women Academically and Professionally,"preprint, January, 2002.

14. Steele, C.M., Spencer, S.J., and Aronson, J., "Contending with images of one's group: The psychology of stereotype and social identity threat," Invited submission to Advances in Experimental Social Psychology, will be published in 2002 .

15. Wolfe, C.T., and Spencer, S.J., "Stereotypes and Prejudice: Their Overt and Subtle Influence in the Classroom,” American Behavioral Scientist, vol. 40, pp. 176-186, 1996.

\section{Biographies}

Dr. Amy E. Bell received her Ph.D. in electrical engineering from the University of Michigan in 1997. She earned her bachelor's and master's degrees from the University of Pittsburgh. Dr. Bell's research interests include: image compression, wavelet modulation, position determination in wireless networks and engineering education. She has received two awards for teaching excellence and a 1999 NSF CAREER award.

Dr. Steven J. Spencer received his Ph.D. in social psychology from the University of Michigan in 1993. He earned his bachelor's degree from Hope College. Dr. Spencer's research interests include stereotyping and prejudice, selfesteem, the role of motivation in the implicit processing of information, and stereotype threat.

Proceedings of the 2002 American Society for Engineering Education Annual Conference \& Exposition Copyright $($ ) 2002, American Society for Engineering Education 